\title{
DOSES E ÉPOCAS DE APLICAÇÃO DE NITROGÊNIO EM ARROZ DE VÁRZEA ${ }^{1}$
}

\author{
Dâmaris Vieira Oliveira Fabre², Antônio Carlos Centeno Cordeiro ${ }^{3}$, \\ Gilvan Barbosa Ferreira ${ }^{3}$, Aloísio Alcântara Vilarinho ${ }^{3}$, Roberto Dantas de Medeiros ${ }^{3}$
}

\begin{abstract}
NITROGEN DOSES AND

APPLICATION TIMES IN LOWLAND RICE

The most outstanding crop, concerning agribusiness in the Roraima State, is lowland rice. Therefore, the recommendation of new cultivars, as well as the study of correct handling for nitrogen fertilizing, are important to maximize grain yield and reduce production costs and environmental impacts. Thus, the objective of this study was to identify the nitrogen doses and application times most adjusted to the rice cultivar BRS Jaçanã, in Roraima lowlands. The experiment took place at the Santa Cecília Farm, a lowland area of the Rio Branco river, in Cantá, Roraima State, Brazil, from December (2007) to March (2008), on a tb distrophic haplic gleissol. The experiments were conducted under a split-plot scheme, with plots displayed under a randomized blocks design with four replicates. Treatments consisted of four $\mathrm{N}$ doses $\left(50 \mathrm{~kg} \mathrm{ha}^{-1}, 100 \mathrm{~kg} \mathrm{ha}^{-1}, 150 \mathrm{~kg} \mathrm{ha}^{-1}\right.$, and $\left.200 \mathrm{~kg} \mathrm{ha}^{-1}\right)$, combined with four application times: E1 - half dose at sowing and half 45 days after emergence (dae); E2 - half dose 15 days after emergence (dae) and half 45 days after emergence (dae); E3 - one application 15 days after emergence (dae); and E4 - one application 45 days after emergence (dae), totalizing 16 treatments and 64 experimental units. Concerning the BRS Jaçanã lowland rice cultivar, the best combination was the application of $118 \mathrm{~kg} \mathrm{ha}^{-1}$ of nitrogen, half at sowing and half 45 days after emergence.
\end{abstract}

KEY-WORDS: Oryza sativa L.; lowland rice; maximum economic yield.

\section{INTRODUÇÃO}

O arroz é um dos cereais de maior importância social e econômica para o mundo, sendo responsável pela alimentação de dois terços da população mundial, fornecendo, aproximadamente, $20 \%$ da energia e $15 \%$ da proteína per capta necessárias ao ser humano (Duarte 2006). O Brasil é o nono produtor mundial e o maior da América Latina, responsável por $88 \%$ da produção do Mercosul. Esta produção é originária,

\section{RESUMO}

No Estado de Roraima, a cultura que mais se destaca no setor do agronegócio é a do arroz irrigado por inundação. Por isto, tanto a recomendação de novas cultivares, quanto o estudo do manejo correto da adubação nitrogenada são importantes para a maximização da produtividade de grãos e redução de custos de produção e impactos ambientais. Assim, o objetivo deste trabalho foi identificar as doses e épocas de aplicação de nitrogênio mais adequadas para a cultivar de arroz BRS Jaçanã, em várzea de Roraima. O experimento foi conduzido na Fazenda Santa Cecília, em área de várzea do Rio Branco, no município de Cantá, no período de dezembro de 2007 a março de 2008, em Gleissolo Háplico tb distrófíco. Utilizaram-se parcelas subdivididas, distribuídas conforme delineamento em blocos casualizados, com quatro repetições. Os tratamentos foram constituídos de quatro doses de N (50 kg ha ${ }^{-1}, 100 \mathrm{~kg} \mathrm{ha}^{-1}, 150 \mathrm{~kg} \mathrm{ha}^{-1}$ e $\left.200 \mathrm{~kg} \mathrm{ha}^{-1}\right)$, como subparcelas, combinadas com quatro épocas de aplicação, como parcelas: E1 - metade da dose na semeadura e metade aos 45 dias após a emergência (dae); E2 - metade da dose aos 15 e metade aos 45 dae; E3 - uma aplicação, aos 15 dae; e E4 - uma aplicação, aos 45 dae, totalizando 16 tratamentos e 64 unidades experimentais. Para a cultivar de arroz irrigado BRS Jaçanã, a melhor combinação foi a aplicação de $118 \mathrm{~kg} \mathrm{ha}^{-1}$ de $\mathrm{N}$, distribuídos metade na semeadura e metade aos 45 dias após a emergência.

PALAVRAS-CHAVE: Oryza sativa L.; arroz irrigado; produtividade máxima econômica.

principalmente, das lavouras de arroz irrigado em várzeas do Sul do País, onde o Estado do Rio Grande do Sul é responsável por mais da metade da produção brasileira (Azambuja et al. 2004).

Em Roraima, o arroz irrigado cultivado em várzeas é um dos produtos de maior importância do setor agrícola, pois possui a cadeia do agronegócio bem definida, com a formação e estruturação de várias agroindústrias, as quais, além de abastecer o mercado local, exportam para outros Estados da

1. Trabalho recebido em out./2009 e aceito para publicação em jan./2011 (nº registro: PAT 7776/ DOI 10.5216/pat.v41i1.7776).

2. Roraima Agrofrutas, Boa Vista, RR, Brasil. E-mail: damarisoliveira12@hotmail.com.

3. Embrapa Roraima, Boa Vista, RR, Brasil.E-mails: acarlos@cpafrr.embrapa.br, gilvan@cpafrr.embrapa.br, aloisio@cpafrr.embrapa.br, roberto@cpafrr.embrapa.br. 
Região Norte, principalmente para o Amazonas. Na safra 2007/2008, foram colhidos cerca de 24.000 hectares, gerando uma produção de 150.000 toneladas de arroz em casca, com produtividade média de $6.350 \mathrm{~kg} \mathrm{ha}^{-1}$ (Cordeiro et al. 2007).

Por outro lado, embora o agronegócio do arroz desfrute de condições favoráveis ao seu desenvolvimento, existem fatores de produção que podem restringir esta expansão, dentre eles o preço de alguns insumos, como o do óleo diesel e fertilizantes, que, juntos, correspondem a cerca de $42 \%$ do custo de produção total por hectare (Banco da Amazônia 2006).

No caso dos fertilizantes, a importância do nitrogênio para o arroz irrigado é indiscutível, já que é o nutriente que a planta de arroz acumula em maior quantidade, com exceção do potássio (Fageria et al. 2007). Em Roraima, segundo Medeiros et al. (2007a), o nitrogênio é um dos elementos mais limitantes para o cultivo do arroz em várzea, exigindo a aplicação de doses elevadas, para que ocorra o desenvolvimento adequado da cultura, em termos de perfilhamento e produtividade de grãos.

Entretanto, deve-se considerar que a recuperação de nitrogênio pelo arroz inundado em solo de várzea situa-se, segundo Fageria \& Baligar (2001), em torno de $40 \%$. Nesta condição, Fageria et al. (2007) citam que o uso racional da adubação nitrogenada é fundamental, não somente para aumentar a eficiência da recuperação, mas, também, para aumentar a produtividade das culturas e diminuir o custo de produção e os riscos de poluição ambiental. Neste sentido, a adequação da quantidade aplicada, na época apropriada, pode aumentar a eficiência de recuperação de nitrogênio.

No sistema de condução de lavoura de arroz irrigado em Roraima, a adubação nitrogenada em cobertura é realizada em duas épocas: início do perfilhamento e iniciação do primórdio floral, para todas as cultivares utilizadas. Por outro lado, na literatura, são verificadas recomendações com diferenças entre cultivares, quanto à capacidade de extração e resposta a doses de nitrogênio. Medeiros et al. (2007a), avaliando a resposta de cultivares precoces de arroz irrigado (BRS Fronteira e Roraima) a doses de nitrogênio aplicadas em cobertura, concluíram que as doses de $145 \mathrm{~kg} \mathrm{ha}^{-1}$ e $161 \mathrm{~kg} \mathrm{ha}^{-1} \mathrm{de} \mathrm{N}$ foram as mais eficientes e econômicas, respectivamente, para as duas cultivares. Já Medeiros et al. (2007b), avaliando o rendimento das cultivares de arroz irrigado de ciclo médio (BRS Jaburu) e de ciclo precoce (IRGA 417), concluíram que a dose mais econômica e eficiente de nitrogênio em cobertura foi de $145 \mathrm{~kg} \mathrm{ha}^{-1}$, para as duas cultivares avaliadas.

A diferença entre genótipos de arroz irrigado, quanto ao uso do nitrogênio, foi, também, relatada por Fageria et al. (2003a), que, avaliando a resposta de genótipos de arroz irrigado testados na Fazenda Palmital, da Embrapa Arroz e Feijão, verificaram que os mesmos foram divididos em dois grupos, com resposta quadrática ou linear. Dois genótipos apresentaram resposta quadrática, sendo a maior produtividade a da linhagem CNAi 8569, obtida com $156 \mathrm{~kg} \mathrm{ha}^{-1}$ de N, e a da cultivar BRS Biguá, que ocorreu fora da faixa das doses de $\mathrm{N}$ testadas $\left(0-200 \mathrm{~kg} \mathrm{ha}^{-1}\right)$. Com relação à resposta linear, a linhagem CNAi 9018 foi mais produtiva que os demais genótipos testados, tanto com baixas como com altas doses de N. Concluíram, então, que existe diferença quanto às necessidades de nitrogênio pelos genótipos, para a produção de grãos.

A recomendação de adubação nitrogenada, para a maior produtividade de arroz irrigado, é resultado da combinação da dose e época de aplicação apropriada. A dose propicia a obtenção de produtividade máxima econômica e a época correta aumenta sua eficiência de utilização. Em experimentos conduzidos em diversos locais, na região tropical, Fageria et al. (2003a) verificaram que as maiores produtividades foram obtidas quando o nitrogênio foi aplicado na semeadura, juntamente com o fósforo e o potássio, e em duas coberturas suplementares, ou seja, por ocasião do perfilhamento e na diferenciação do primórdio floral. Outra alternativa seria a aplicação parcelada de metade do $\mathrm{N}$ na semeadura e a outra metade no estádio de perfilhamento, entretanto, outros trabalhos na literatura mostram algumas variações, com relação à melhor época de aplicação (Bronson et al. 2000, Fageria \& Baligar 2005).

O nitrogênio é um nutriente móvel no solo e muda de concentração em função do clima, solo e tempo. Portanto, as recomendações de adubação nitrogenada são feitas com base na resposta da cultura à aplicação deste nutriente, em condições de campo. Em trabalhos realizados durante três anos, Fageria et al. (2003b) concluíram que a dose adequada de nitrogênio para a cultura do arroz irrigado situa-se na faixa $90-120 \mathrm{~kg} \mathrm{ha}^{-1} \mathrm{de} \mathrm{N}$, para as principais regiões produtoras de arroz no Brasil.

Por outro lado, é preciso considerar a ocorrência de doenças, na combinação de doses de nitrogênio e épocas de aplicação. Cornélio et al. (2007) concluíram que, para o arroz de terras altas, no caso de 
parcelamento de nitrogênio, deve-se aplicar a maior quantidade próximo à diferenciação do primórdio floral, onde o aproveitamento deste elemento é mais eficiente, embora também predisponha a cultura a maior ocorrência de brusone do pescoço da panícula.

Em Roraima, ainda não foram avaliadas épocas de aplicação de nitrogênio em cobertura, para o arroz irrigado, sendo que os principais resultados estão relacionados às doses de nitrogênio (Medeiros et al. 2007a e 2007b)

Assim, o objetivo deste estudo foi identificar doses e épocas de aplicação de nitrogênio mais adequadas para a cultivar de arroz irrigado BRS Jaçanã, em várzea de Roraima, visando a maximizar a produtividade de grãos e, concomitantemente, reduzir custos de produção e possíveis impactos ambientais.

\section{MATERIAL E MÉTODOS}

O experimento foi conduzido na Fazenda Santa Cecília, em área de várzea do Rio Branco, no município de Cantá (248'27,484'N e 60³9'17'564'”W), de dezembro de 2007 a março de 2008, em solo do tipo Gleissolo Háplico tb distrófico, área de segundo ano, com as seguintes características químicas e físicas: $\mathrm{pH}=5,2 ; \mathrm{Ca}=0,64 \mathrm{cmol}_{\mathrm{c}} \mathrm{dm}^{-3} ; \mathrm{Mg}=0,28 \mathrm{cmol}_{\mathrm{c}} \mathrm{dm}^{-3}$; $\mathrm{K}=0,07 \mathrm{cmol} \mathrm{dm}^{-3} ; \mathrm{Al}=1,83 \mathrm{cmol} \mathrm{dm}^{-3} ; \mathrm{P}=$ $2,16 \mathrm{mg} \mathrm{dm}^{-3} ; \mathrm{MO}=11,9 \mathrm{~g} \mathrm{dm}^{-3}$; areia $=7 \mathrm{dag} \mathrm{kg}^{-1}$; Silte $=50 \mathrm{dag} \mathrm{kg}^{-1} ;$ e argila $=43 \mathrm{dag} \mathrm{kg}^{-1}$.

Os tratamentos constaram de quatro doses de nitrogênio (ureia com $45 \%$ de $\mathrm{N}$ e $\mathrm{N} 1=$ $50 \mathrm{~kg} \mathrm{ha}^{-1} ; \mathrm{N} 2=100 \mathrm{~kg} \mathrm{ha}^{-1} ; \mathrm{N} 3=150 \mathrm{~kg} \mathrm{ha}^{-1} ; \mathrm{e} \mathrm{N} 4=$ $200 \mathrm{~kg} \mathrm{ha}^{-1}$ ), combinadas com quatro épocas de aplicação: E1 - metade da dose na semeadura e metade aos 45 dias após a emergência (dae); E2 - metade da dose aos 15 e aos 45 dae; E3 - uma aplicação, aos 15 dae; e E4 - uma aplicação, aos 45 dae. A aplicação aos 15 dias correspondeu ao início do perfilhamento e, aos 45 dias, à iniciação do primórdio floral.

$\mathrm{O}$ experimento foi conduzido em parcelas subdivididas, com as parcelas distribuídas conforme o delineamento de blocos casualizados, com quatro repetições, totalizando 16 tratamentos e 64 unidades experimentais. Nas parcelas, foram testadas as épocas de aplicação e, nas subparcelas, as doses de nitrogênio. As parcelas tiveram as dimensões de $4,20 \mathrm{~m} \mathrm{x}$ $12,00 \mathrm{~m}\left(50,40 \mathrm{~m}^{2}\right)$ e as subparcelas as dimensões de $4,20 \mathrm{~m} \times 3,00 \mathrm{~m}\left(12,60 \mathrm{~m}^{2}\right)$, com área útil de 3,60 m x $2,00 \mathrm{~m}\left(7,20 \mathrm{~m}^{2}\right)$. O espaçamento entrelinhas foi de $0,30 \mathrm{~m}$, com densidade de 100 sementes por metro.
Foi utilizada a cultivar de arroz irrigado BRS Jaçanã, lançada em Roraima por Cordeiro \& Medeiros (2008). Esta cultivar destaca-se pela ótima qualidade de grãos, boa estabilidade e alto rendimento de grãos inteiros e resistência ao acamamento, além de apresentar maior resistência à brusone que as demais cultivares em uso em Roraima.

A adubação básica na semeadura, para todos os tratamentos avaliados, constou de $450 \mathrm{~kg} \mathrm{ha}^{-1} \mathrm{da}$ fórmula $04-28-20+0,5 \%$ de $\mathrm{Zn}$. No ano anterior à análise do solo apresentada, a área experimental tinha recebido a aplicação de $1.000 \mathrm{~kg} \mathrm{ha}^{-1}$ de calcário dolomítico (PRNT 90\%). O sistema de irrigação utilizado foi por inundação contínua, com lâmina de água iniciada aos 15 dias após a emergência das plântulas e interrompida aos 20 dias após o completo florescimento.

Foram avaliadas as seguintes características: altura média de plantas (cm) (ALT); massa de 100 grãos (g) (M100); número de panículas por $\mathrm{m}^{2}$ (NPAN); número de grãos por panícula (NGP); percentagem de espiguetas granadas por panículas (\% GC); incidência de doenças como brusone nas folhas (BF) e mancha de grãos (MG), avaliadas por escalas de notas visuais variando de 0 a 9; e produtividade de grãos em casca $\left(\mathrm{kg} \mathrm{ha}^{-1}\right)$ (PROD). A coleta dos dados foi efetuada de acordo com a metodologia preconizada no Standard Evaluation System For Rice (IRRI 1996) e no Manual de Métodos de Pesquisa em Arroz (Embrapa 1977).

Os dados obtidos foram submetidos a análise de variância, através do teste $\mathrm{F}$ e teste Tukey, a 5\%, para o fator épocas de aplicação, e análise de regressão polinomial, para o fator doses de $\mathrm{N}$. Todas as análises foram realizadas com o auxílio do software Genes (Cruz 2001).

\section{RESULTADOS E DISCUSSÃO}

Pelos resultados obtidos nas análises de variância, foram detectadas interações significativas entre doses e épocas de aplicação de nitrogênio, para altura média de plantas, número de panículas $\mathrm{m}^{-2}$, número de grãos por panícula e produtividade de grãos (dados não demonstrados). As demais características analisadas não apresentaram efeito significativo para nenhuma das fontes de variação.

Como houve interação, procederam-se, então, às análises de regressão, desdobrando-se os efeitos das doses de $\mathrm{N}$ dentro de cada época de aplicação, 
apenas para as características mencionadas anteriormente, já que, para as demais, não foi detectado efeito significativo da interação.

\section{Altura de planta}

Observou-se que as doses de nitrogênio promoveram aumento na altura das plantas, nas diferentes épocas de aplicação, pois, quando aplicados apenas $50 \mathrm{~kg} \mathrm{ha}^{-1}$ de $\mathrm{N}$, a altura das plantas, de um modo geral, foi menor, em relação às médias obtidas com as demais doses. Com doses mais elevadas, houve aumento na altura das plantas, no entanto, não foi observado acamamento (Figuras 1A, 1B, 1C e 1D). Resultados semelhantes foram relatados por Medeiros et al. (2007a), que verificaram aumento na altura de plantas das cultivares de arroz irrigado BRS Fronteira e Roraima, com a aplicação de doses crescentes de $\mathrm{N}$ em cobertura, sem propiciar, no entanto, acamamento das plantas. Pela análise das posições de intercepto das curvas de crescimento em altura e seu comportamento frente às doses de
$\mathrm{N}$ aplicadas (Figuras 1A, 1B, 1C e 1D), pode-se observar que houve tendência de maior crescimento vegetativo, quando a maior parte do $\mathrm{N}$ foi aplicada aos 15 dae (Figura 1B), e menor, quando a aplicação ocorreu aos 45 dae (Figura 1D). Provavelmente, em condições onde o elemento é limitante, a aplicação precoce de $\mathrm{N}$ no perfilhamento permite uma maior recuperação do nutriente pela cultura e melhoria no seu estado nutricional, provocando maior crescimento vegetativo, porém, sem risco de acamamento, na cultivar BRS Jaçanã. Isto é importante para haver maior absorção de luz, maior taxa de fotossíntese e, consequentemente, maior produtividade.

Pela derivação das equações de regressão, que ajustaram-se a modelos quadráticos (Figuras $1 \mathrm{~A}$ e $1 \mathrm{D}$ - Épocas 1 e 4), foram obtidos os valores máximos de resposta ao incremento de doses de $\mathrm{N}$ de $154,42 \mathrm{~kg}$, para altura de planta de $100,25 \mathrm{~cm}$, e $112,23 \mathrm{~kg}$, para altura de planta de $89,94 \mathrm{~cm}$, respectivamente. Mesmo com os pontos máximos das doses de N, para as duas épocas, a altura média das plantas foi considerada adequada para o arroz irrigado, o
Época 1

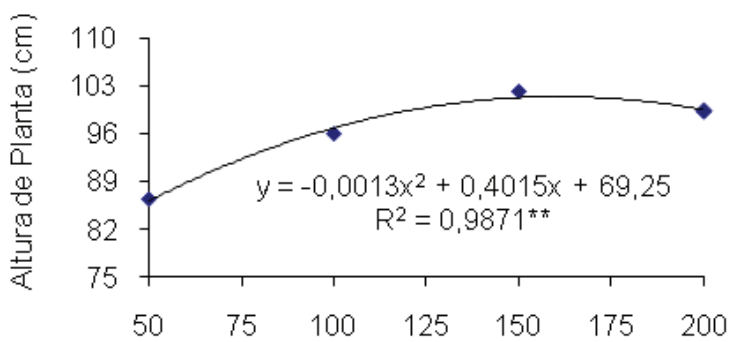

Época 3

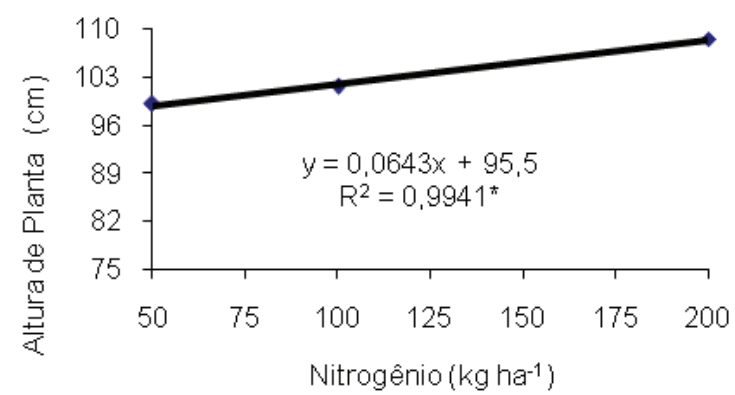

A

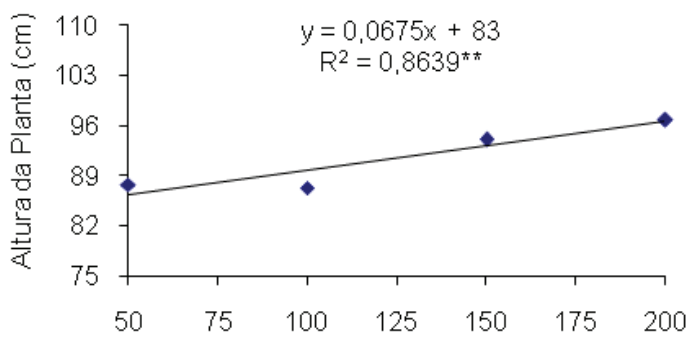

Época 4

$\mathrm{D}$

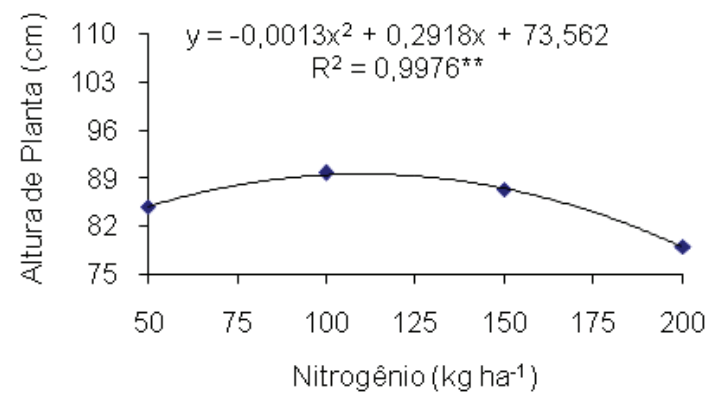

Figura 1. Altura média de plantas de arroz irrigado (BRS Jaçanã), em função de doses de N, em quatro épocas de aplicação: A) Época 1: $1 / 2$ na semeadura e $1 / 2$ aos 45 dias após a emergência (dae); B) Época 2: 1/2 aos 15 e $1 / 2$ aos 45 dae; C) Época 3: dose única, aos 15 dae; D) Época 4: dose única, aos 45 dae. * e ** Significativo a 5\% e 1\%, respectivamente, pelo teste $\mathrm{F}$ (Cantá, RR, safra 2007/2008). 
que já era esperado, uma vez que, em programas de melhoramento, um dos objetivos é a resistência ao acamamento e resposta à adubação, o que implica na seleção de linhagens com baixa altura de planta $(85-100 \mathrm{~cm})$ (Morais et al. 2006).

Por outro lado, a altura média observada foi de 93,42 cm, com mínima de $76 \mathrm{~cm}$ e máxima de $112 \mathrm{~cm}$, na média de todas as épocas de aplicação e doses de $\mathrm{N}$ utilizadas, ou seja, compatível com o observado para a cultivar BRS Jaçanã, por Cutrim et al. (2007), que descreveram altura média de $103 \mathrm{~cm}$, e, também, por Cordeiro \& Medeiros (2008), que, na recomendação da mesma cultivar para Roraima, relataram altura média de $85 \mathrm{~cm}$.

Número de panículas $m^{-2}$

As médias do número de panículas $\mathrm{m}^{-2}$, em função de doses de N, nas diferentes épocas de aplicação testadas, ajustaram-se a modelos de regressão linear e quadrática. No entanto, o modelo quadrático foi o escolhido para a interpretação dos resultados, considerando-se que este explica melhor a variação

Época 1

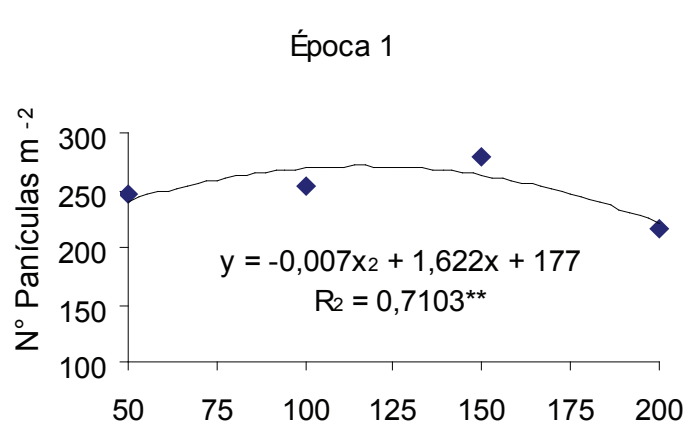

Época 3

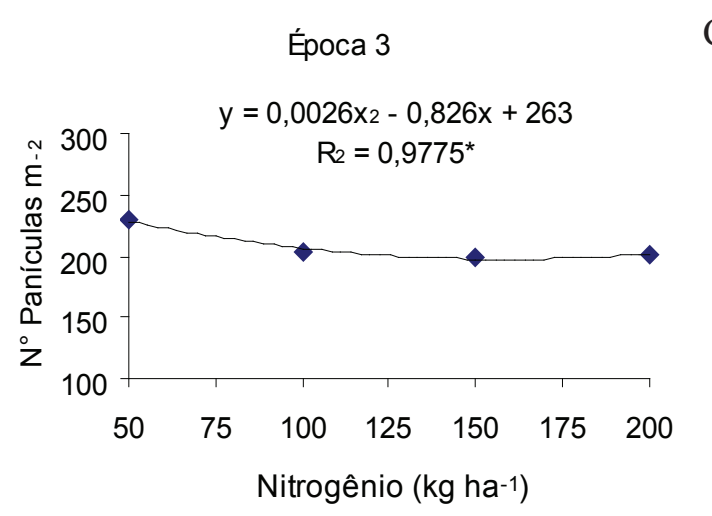

dos resultados e tem mais aderência a modelos biológicos de crescimento das plantas, em resposta a doses de $\mathrm{N}$ (Figura 2). A média geral do número de panículas foi de 222,62, com mínima de 167 e máxima de 349 panículas $\mathrm{m}^{-2}$, independentemente da dose de $\mathrm{N}$ e época de aplicação.

Para as épocas E1, E2 e E4, o número de panículas $\mathrm{m}^{-2}$ aumentou, com o incremento de doses de nitrogênio, até $115,9 \mathrm{~kg} \mathrm{ha}^{-1}, 148,6 \mathrm{~kg} \mathrm{ha}^{-1} \mathrm{e}$ $144,7 \mathrm{~kg} \mathrm{ha}^{-1}$, com máximas de 271,0; 222,7; e 239,0 panículas $\mathrm{m}^{-2}$, respectivamente. Por outro lado, na Época 3, as doses de $\mathrm{N}$ promoveram redução no número de panículas $\mathrm{m}^{-2}$, atingindo valor mínimo na dose de $158,9 \mathrm{~kg} \mathrm{ha}^{-1}$ de N, com 197,4 panículas $\mathrm{m}^{-2}$, tendendo a se estabilizar, considerando-se a amplitude das doses usadas neste trabalho (Figuras 2A, 2B, 2C e 2D).

Conforme Fageria \& Baligar (2001) e Fageria et al. (2003b), a eficiência de recuperação de N, em arroz em várzea inundada, é de, aproximadamente, $40 \%$, e, nesta situação, espera-se que exista maior resposta à aplicação de $\mathrm{N}$, quando este é parcelado, e necessidade de maiores doses, quando ele é aplicado

A

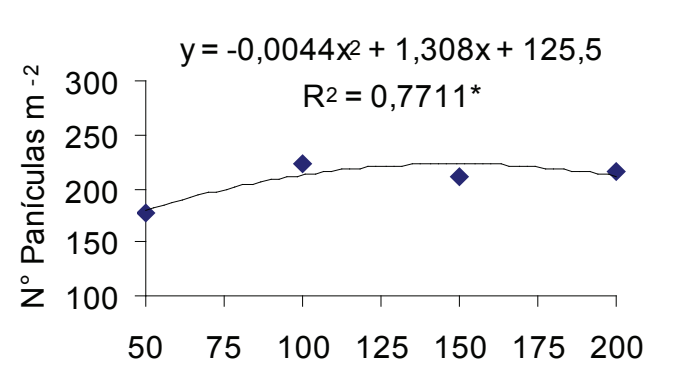

B

$\mathrm{C}$

Época 4

D

Figura 2. Número de panículas $\mathrm{m}^{-2}$ (NPAN), em função da aplicação de doses de nitrogênio, em quatro épocas, sobre a cultivar de arroz irrigado BRS Jaçanã: A) Época 1: 1/2 na semeadura e aos 45 dias após a emergência (dae); B) Época 2: 1/2 aos 15 e aos 45 dae; C) Época 3: dose única, aos 15 dae; D) Época 4: dose única, aos 45 dae. * e ** Significativo a 5\% e 1\%, respectivamente, pelo teste F (Cantá, RR, safra 2007/2008). 
em dose única, visto que o elemento é um nutriente móvel no sistema solo-planta e se perde facilmente por lixiviação, volatilização e desnitrificação.

Medeiros et al. (2007a) também não verificaram diferenças significativas para o número de panículas $\mathrm{m}^{-2}$, para as cultivares BRS Fronteira, Roraima, BRS Jaburu e IRGA 417, com o aumento de doses de nitrogênio, embora tenha existido tendência de crescimento até a dose de $200 \mathrm{~kg} \mathrm{ha}^{-1}$ de $\mathrm{N}$.

\section{Número de grãos por panícula}

Para o componente de produção número de grãos por panícula, só foram obtidos, na análise de regressão, ajustes a curvas lineares e/ou quadráticas para as épocas E3 e E1, respectivamente. Para as demais, os efeitos não foram significativos. Verificou-se que o número de grãos por panícula aumentou até a dose de $167,9 \mathrm{~kg} \mathrm{ha}^{-1}$ de N, alcançando 70,7 grãos panícula $^{-1}$, quando a adubação foi realizada $1 / 2$ na semeadura e $1 / 2$ aos 45 dae, na Época 1 (Figura 3A). No entanto, quando a adubação foi realizada em dose única, aos 15 dae (Época 3), o crescimento foi linear, ou seja, à medida em que se aumentou a dose de $\mathrm{N}$, houve aumento no número de grãos por panícula de 59,0 a 92, 0 unidades (Figura 3B), nos limites das doses de $\mathrm{N}$ utilizadas. $\mathrm{O}$ número de grãos por panícula produzido foi maior com a adubação efetuada aos 15 dae (início do perfilhamento) do que quando parcelada na semeadura e aos 45 dae (primórdio floral). Isto demonstrou que a adubação na Época 3 promoveu um maior crescimento na planta (Figura 1C) e que, muito embora tenha apresentado pequeno número de panículas (Figura 2C), apresentou panículas com maior número de grãos (Figura $3 \mathrm{~B}$ ). $\mathrm{O}$ início do perfilhamento é mais importante para a definição do número de perfilhos do que para a definição do número de grãos por panícula. Como a cultivar BRS Jaçanã é de ciclo precoce, apresenta período vegetativo mais curto e, nesta situação, as cultivares são menos perfilhadoras, mas, em compensação, podem apresentar panículas mais longas, com maior número de grãos.

No entanto, avaliando-se o número de grãos panícula $^{-1}$, em função das épocas de aplicação (Tabela 1), verifica-se que, em média, independentemente da dose de $\mathrm{N}$ utilizada, os maiores valores de grãos panícula-1 ocorreram nas Épocas 2 e 4, sugerindo que a aplicação de $\mathrm{N}$, aos 45 dae, é importante para aumentar o número de grãos panícula ${ }^{-1}$, haja vista ser, nesta fase, que ocorre o primórdio floral e a definição do número de grãos que as panículas apresentarão. Isto é importante, uma vez que um maior número de grãos por panícula pode contribuir para aumentar a produtividade da cultura (Fageria et al. 2003a).

\section{Produtividade de grãos}

Houve efeito significativo das doses de $\mathrm{N}$ e interação épocas de aplicação x doses sobre a produtividade de grãos de arroz em casca. No entanto, não foram observadas respostas significativas, com relação às épocas de aplicação. As estimativas das médias para produtividade de grãos, em função das doses de $\mathrm{N}$ aplicadas em todas as épocas de avaliação, ajustaram-se a modelos de regressão quadráticos (Figuras 4A, 4B, 4C e 4D). Entretanto, na Época 4, o efeito quadrático foi significativo a $6,4 \%$, pelo teste $\mathrm{F}$, sendo possível ajustar a equação

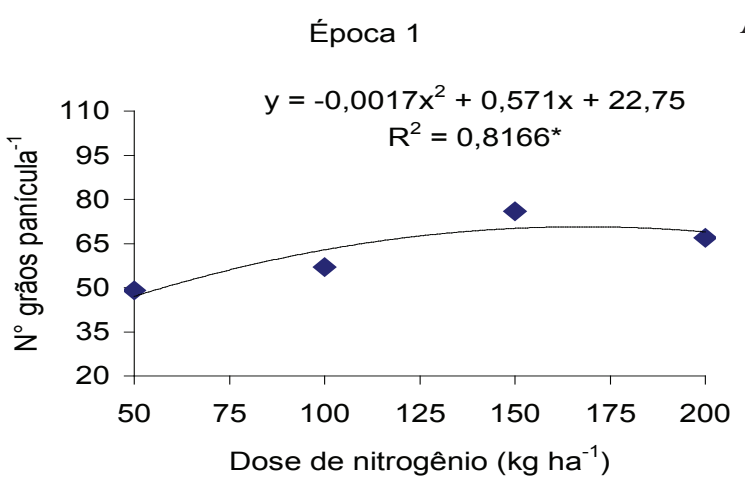

A

Época 3

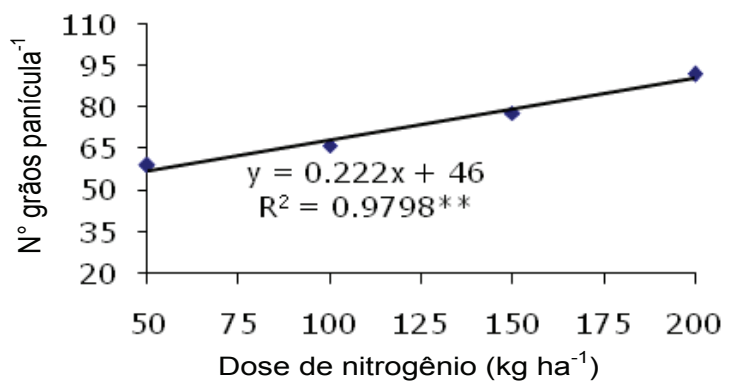

Figura 3. Número de grãos por panícula da cultivar de arroz irrigado BRS Jaçanã, em função de doses de nitrogênio e épocas de aplicação: A) Época 1: 1/2 na semeadura e 1/2 aos 45 dias após a emergência (dae); B) Época 3: dose única, aos 15 dae. * e ** Significativos a 5\% e 1\%, respectivamente, pelo teste F (Cantá, RR, safra 2007/2008). 
Tabela 1. Médias do número de grãos por panícula, proporcionadas pela cultivar BRS Jaçanã, em quatro épocas de aplicação de nitrogênio em cobertura, em várzea de Roraima (Cantá, RR, safra 2007/2008).

\begin{tabular}{ccccc}
\hline \multirow{2}{*}{ Épocas } & \multicolumn{4}{c}{$\begin{array}{c}\text { Número de grãos panícula } \\
\text { kg ha }\end{array}$} \\
\cline { 2 - 5 } & 50 & 100 & 150 & 200 \\
\hline E1 & $49,5 \mathrm{~b}$ & $57,0 \mathrm{c}$ & $76,25 \mathrm{a}$ & $67,25 \mathrm{~b}$ \\
E2 & $89,5 \mathrm{a}$ & $82,5 \mathrm{ab}$ & $95,25 \mathrm{a}$ & $94,75 \mathrm{a}$ \\
E3 & $59,0 \mathrm{~b}$ & $66,0 \mathrm{bc}$ & $77,75 \mathrm{a}$ & $91,75 \mathrm{a}$ \\
E4 & $83,2 \mathrm{a}$ & $91,5 \mathrm{a}$ & $80,25 \mathrm{a}$ & $90,25 \mathrm{a}$ \\
\hline
\end{tabular}

E1: metade da dose na semeadura e metade aos 45 dias após a emergência; E2: metade da dose aos 15 dias e metade aos 45 dias após a emergência; E3: uma aplicação, aos 15 dias após a emergência; E4: uma aplicação, aos 45 dias após a emergência. Médias seguidas da mesma letra, na mesma coluna, não diferem entre si, a $5 \%$, pelo teste Tukey.

de regressão com $\mathrm{R}^{2}$ de $75,65 \%$, demonstrando boa precisão (Figura 4D). Estes resultados corroboram a afirmação de Fageria et al. (2007), que verificaram efeitos significativos e quadráticos da aplicação de $\mathrm{N}$, na produtividade de grãos de 12 genótipos de arroz irrigado por inundação, usando as doses $0 \mathrm{~kg} \mathrm{ha}^{-1}$, $50 \mathrm{~kg} \mathrm{ha}^{-1}, 100 \mathrm{~kg} \mathrm{ha}^{-1}, 150 \mathrm{~kg} \mathrm{ha}^{-1}$ e $200 \mathrm{~kg} \mathrm{ha}^{-1}$.
A produtividade média obtida para a cultivar BRS Jaçanã, no experimento, independentemente da dose e época de aplicação, foi de $5.543 \mathrm{~kg} \mathrm{ha}^{-1}$, com mínima de $3.896 \mathrm{~kg} \mathrm{ha}^{-1}$ e máxima de $7.162 \mathrm{~kg} \mathrm{ha}^{-1}$. Cordeiro \& Medeiros (2008), em três anos de avaliação desta cultivar, em Ensaio de Valor de Cultivo e Uso (VCU) conduzido em Roraima, obtiveram média de $6.607 \mathrm{~kg} \mathrm{ha}^{-1}$, valor próximo aos encontrados neste trabalho.

$\mathrm{Na}$ avaliação das produtividades médias, em função de doses de N, em cada época de aplicação, foram obtidas, por meio da derivação das equações de regressão, as doses de máxima eficiência de produção física ou dose máxima física, ou seja, aquelas até onde houve resposta em aumento da produtividade, em função do acréscimo de $\mathrm{N}$ na adubação de cobertura (Tabela 2). Observou-se que elas variaram de $128,5 \mathrm{~kg} \mathrm{ha}^{-1}$ a 153,2 $\mathrm{kg} \mathrm{ha}^{-1}$, com produtividades de $5.549 \mathrm{~kg} \mathrm{ha}^{-1}$ a $6.544 \mathrm{~kg} \mathrm{ha}^{-1}$. Vahl (1999), no Rio Grande do Sul, obteve produtividade máxima de cultivares de arroz irrigado por inundação com a aplicação de $114 \mathrm{~kg} \mathrm{ha}^{-1}$ a $126 \mathrm{~kg} \mathrm{ha}^{-1}$ de $\mathrm{N}$.
Época 1

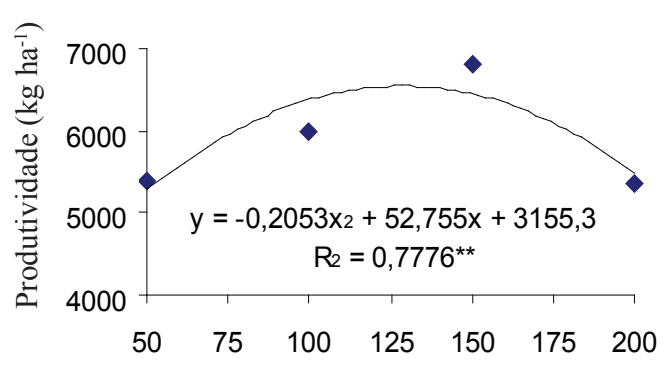

Época 3

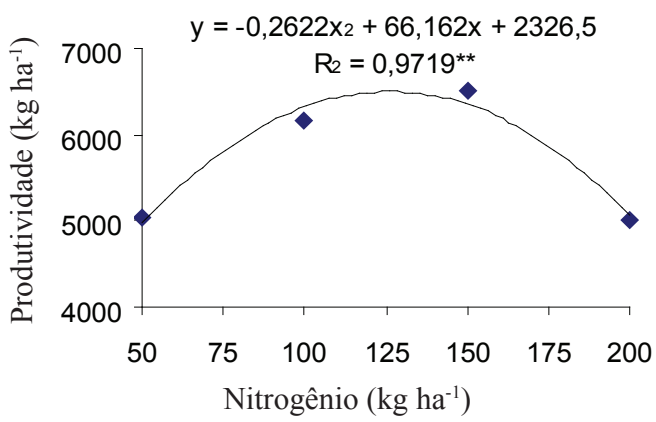

Época 2

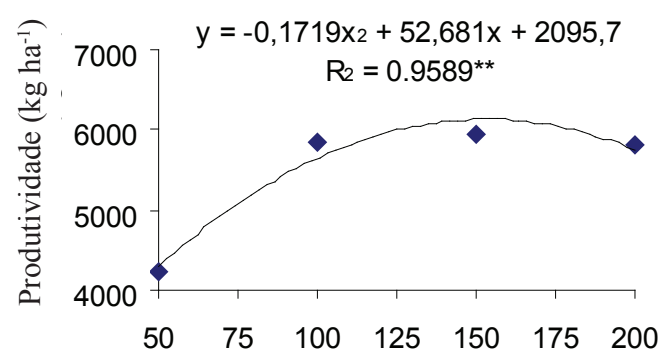

C

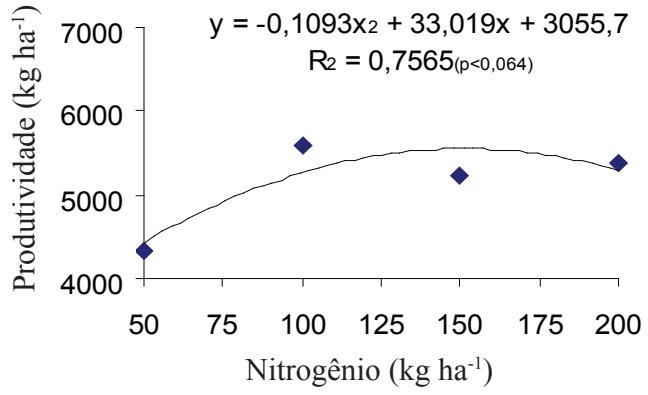

Figura 4. Efeito de doses de N combinadas com quatro épocas de aplicação, sobre a produtividade de grãos da cultivar de arroz irrigado BRS Jaçanã: A) Época 1: 1/2 na semeadura e aos 45 dias após a emergência (dae); B) Época 2: 1/2 aos 15 e aos 45 dae; C: Época 3: dose única, aos 15 dae; D) Época 4: dose única, aos 45 dae. * e ** Significativo $(\mathrm{p}<0,06$ e p $<0,01$, respectivamente), pelo teste $\mathrm{F}$ (Cantá, RR, safra 2007/2008). 
Tabela 2. Estimativa de produtividades e doses máximas físicas e máximas econômicas e da eficiência agronômica da adubação com nitrogênio, parcelada em quatro épocas, na BRS Jaçanã, cultivada em várzea de Roraima (Cantá, RR, safra 2007/2008).

\begin{tabular}{|c|c|c|c|c|}
\hline \multirow{2}{*}{ Estimativa } & \multicolumn{4}{|c|}{ Época de adubação nitrogenada ${ }^{1}$} \\
\hline & Época 1 & Época 2 & Época 3 & Época 4 \\
\hline & \multicolumn{4}{|c|}{$\mathrm{kg} \mathrm{ha}^{-1}$} \\
\hline Produtividade de máxima eficiência física & 6544,0 & 6113,0 & 6501,0 & 5549,0 \\
\hline Dose de máxima eficiência de produtividade física & 128,5 & 153,2 & 126,2 & 151,0 \\
\hline Eficiência agronômica máxima física $\left(\mathrm{kg} \mathrm{kg}^{-1}\right)$ & 50,9 & 39,9 & 51,5 & 36,7 \\
\hline Produtividade de máxima eficiência econômica & 6523,0 & 6107,0 & 6484,0 & 5520,0 \\
\hline Dose de máxima eficiência de produtividade econômica & 118,4 & 141,2 & 118,3 & 132,2 \\
\hline Eficiência agronômica máxima econômica $\left(\mathrm{kg} \mathrm{kg}^{-1}\right)$ & 55,1 & 43,2 & 54,8 & 41,8 \\
\hline
\end{tabular}

${ }^{1}$ Época 1: 1/2 da dose na semeadura e aos 45 dias após a emergência (dae); Época 2: 1/2 aos 15 dias e aos 45 dae; Época 3: dose única, aos 15 dae; Época 4: dose única, aos 45 dae. ${ }^{2}$ Eficiência agronômica $=$ Produtividade $\div$ dose, em $\mathrm{kg} \mathrm{kg}^{-1}$, de arroz por $\mathrm{N}$ aplicado.

As doses de máxima eficiência de produção econômica ou dose máxima econômica, calculadas por meio da equação de regressão, quando estas são igualadas ao quociente preço do $\mathrm{kg}$ do nitrogênio/preço do kg do arroz, identifica até que dose de nutriente o incremento de produção resultante paga o custo do adubo aplicado. Elas variaram de 118,4 $\mathrm{kg} \mathrm{ha}^{-1}$ a 141,2 $\mathrm{kg} \mathrm{ha}^{-1}$, com produtividades de máxima eficiência econômica de $5.520 \mathrm{~kg} \mathrm{ha}^{-1}$ a $6.523 \mathrm{~kg} \mathrm{ha}^{-1}$ de arroz (Tabela 2). A eficiência agronômica foi maior com o uso das doses máximas econômicas, sendo menor na Época 4 e maior na Época 1. A aplicação da maior parte do $\mathrm{N}$ aos 45 dae (Época 4) levou à menor altura da planta (Figura1D), aumentou pouco o número de panículas $\mathrm{m}^{-2}$ (Figura 2D) e não teve efeito significativo sobre o número de grãos por panícula, o que resultou na obtenção de maior necessidade de adubo e menor produtividade. Já a aplicação do $\mathrm{N}$ na semeadura e aos 45 dae (primórdio floral) permitiu máximo aproveitamento do nutriente, fazendo a planta crescer de forma equilibrada desde a emergência (Figura 1A), aumentando o número de panículas $\mathrm{m}^{-2}$ (Figura 2A) e de grãos por panícula (Figura 3A), o que resultou na maior produtividade e na menor necessidade de fertilizante nitrogenado.
Por outro lado, a aplicação da maior parte do $\mathrm{N}$ apenas no início do perfilhamento (Época 3) promoveu um rápido crescimento da planta (Figura 1C), o que, provavelmente, reduziu o número de perfilhos $\mathrm{e}$, consequentemente, de panículas $\mathrm{m}^{-2}$ (Figura 2C), porém, permitiu à planta manter panículas com maior número de grãos, que, adicionalmente, responderam linearmente à aplicação do $\mathrm{N}$ (Figura 3B), permitindo a obtenção de boa produtividade $\left(6.501 \mathrm{~kg} \mathrm{ha}^{-1}\right)$, com requerimento mediano de nutriente. Já a Época 2 foi intermediária às últimas duas épocas citadas, tendo aumento menor em crescimento, em resposta ao $\mathrm{N}$ aplicado (Figura 1B), e crescimento do número de panículas $\mathrm{m}^{-2}$ (Figura $2 \mathrm{~B}$ ), sem efeito nos demais componentes de produção, o que resultou em produtividade alta $\left(6.113 \mathrm{~kg} \mathrm{ha}^{-1}\right)$, porém menor do que as obtidas nas Épocas 1 e 3, que permitiram o uso do $\mathrm{N}$ de forma agronômica mais eficiente.

Em termos de retorno econômico (Tabela 3), os melhores resultados foram obtidos com a dose de $\mathrm{N}$ de, aproximadamente, $118 \mathrm{~kg} \mathrm{ha}^{-1}$, que proporcionou os menores custos e, consequentemente, as maiores receitas líquidas. Ressalta-se, ainda, que as produtividades médias de $6.544 \mathrm{~kg} \mathrm{ha}^{-1} \mathrm{e} 6.501 \mathrm{~kg} \mathrm{ha}^{-1}$

Tabela 3. Receita líquida obtida com a aplicação de doses de nitrogênio em cobertura, para a cultivar BRS Jaçanã de arroz irrigado (Cantá, RR, safra 2007/2008).

\begin{tabular}{ccccccc}
\hline \multirow{2}{*}{ Épocas $^{(1)}$} & $\begin{array}{c}\text { Doses de N } \\
\left(\mathrm{kg} \mathrm{ha}^{-1}\right)\end{array}$ & \multicolumn{2}{c}{ Custo ha $^{-1(2)}$} & $\begin{array}{c}\text { Produtividade } \\
\left(\mathrm{kg} \mathrm{ha}^{-1}\right)\end{array}$ & $\begin{array}{c}\mathrm{RB}^{(3)} \\
(\mathrm{R} \$)\end{array}$ & $\begin{array}{c}\mathrm{RL}^{(3)} \\
(\mathrm{R} \$)\end{array}$ \\
\hline E1 & 118,40 & 340,99 & 7,44 & 6.544 & $4.581,00$ & $4.240,01$ \\
E2 & 141,20 & 406,66 & 9,50 & 6.113 & $4.279,10$ & $3.872,44$ \\
E3 & 118,30 & 340,70 & 7,49 & 6.501 & $4.551,00$ & $4.210,30$ \\
E4 & 132,20 & 380,74 & 9,80 & 5.549 & $3.884,30$ & $3.503,56$ \\
\hline
\end{tabular}

(1) E1: $1 / 2$ da dose na semeadura e $1 / 2$ aos 45 dias após a emergência; E2: 1/2 da dose aos 15 dias e 1/2 aos 45 dias após emergência; E3: uma aplicação, aos 15 dias após emergência; e E4: uma aplicação, aos 45 dias após emergência.

(2) Ureia $(45 \%$ de $\mathrm{N})$ a $\mathrm{R} \$ 1,30 / \mathrm{kg}$ (dezembro 2007). Os valores em percentagem referem-se à renda bruta (RB).

${ }^{(3)} \mathrm{RB}$ : renda bruta; RL: renda líquida. Saco do arroz $(50 \mathrm{~kg})$ em casca a R $\$ 35,00$ (fevereiro de 2008). Não foram computados os custos relativos ao nitrogênio existente na formulação básica (04-28-20 + 0,5 Zn) usada para todos os tratamentos. 
representaram $91 \%$ da produtividade máxima obtida no experimento, que foi de $7.162 \mathrm{~kg} \mathrm{ha}^{-1}$. Estes resultados foram semelhantes aos obtidos por Fageria et al. (2007), que, avaliando respostas de arroz irrigado por inundação à aplicação de $\mathrm{N}$, também verificaram que a dose econômica correspondeu a $90 \%$ de produtividade máxima obtida no experimento.

Com base em todos os resultados obtidos, pode-se inferir que, para a cultivar de arroz irrigado BRS Jaçanã, a melhor combinação foi o uso de, aproximadamente, $118 \mathrm{~kg} \mathrm{ha}^{-1} \mathrm{de} \mathrm{N}$, divididos metade na semeadura e metade aos 45 dae (primórdio floral) (Época 1). Experimentos realizados por Machado et al. (2000 apud Scivittaro \& Machado 2004), em Pelotas (RS), durante três anos consecutivos, com quatro linhagens de arroz irrigado por inundação, verificaram que o melhor parcelamento ocorreu com a aplicação da metade da dose na semeadura e o restante por ocasião do início do primórdio floral, corroborando os resultados encontrados no presente trabalho.

Por outro lado, os resultados encontrados, com relação às doses de $\mathrm{N}$, foram diferentes dos encontrados por Medeiros et al. (2007a e 2007b), que, avaliando respostas de cultivares de arroz irrigado em várzea de Roraima, às doses de $50 \mathrm{~kg} \mathrm{ha}^{-1}, 100 \mathrm{~kg} \mathrm{ha}^{-1}$, $200 \mathrm{~kg} \mathrm{ha}^{-1}$ e $300 \mathrm{~kg} \mathrm{ha}^{-1} \mathrm{de} \mathrm{N}$, em ensaios conduzidos durante três anos agrícolas, obtiveram, como doses máximas econômicas, $145 \mathrm{~kg} \mathrm{ha}^{-1} \mathrm{de} \mathrm{N}$, para as cultivares BRS Fronteira, BRS Jaburu e IRGA 417, e $161 \mathrm{~kg} \mathrm{ha}^{-1}$ de N, para a cultivar Roraima, aplicados aos 15 e 45 dias após a emergência. Vale ressaltar, no entanto, que os dados obtidos neste trabalho, quando comparados considerando-se apenas as épocas de aplicação de $\mathrm{N}$ realizadas por Medeiros et al. (2007a e 2007 b), permitem estimar a dose de máxima eficiência econômica em $141 \mathrm{~kg} \mathrm{ha}^{-1}$ (Tabela 2), ou seja, próxima aos valores encontrados por estes autores. Como os resultados obtidos neste trabalho são relativos apenas a um ano agrícola, novos ensaios devem ser conduzidos para confirmação ou não dos dados aqui apresentados.

\section{CONCLUSÃO}

Para o melhor crescimento e produtividade de grãos da cultivar de arroz irrigado BRS Jaçanã, a melhor combinação foi a aplicação de $118 \mathrm{~kg} \mathrm{ha}^{-1} \mathrm{de}$ $\mathrm{N}$, distribuídos metade na semeadura e metade aos 45 dias após a emergência.

\section{REFERÊNCIAS}

AZAMBUJA, I. H. V; VERNETTI JÚNIOR, F. J.; MAGALHÃES JÚNIOR, A. M. Aspectos sócioeconômicos da produção de arroz. In: GOMES, A. S.; MAGALHÃES JÚNIOR, A. M. Arroz irrigado no Sul do Brasil. Brasília, DF: Embrapa Informação Tecnológica, 2004.

BANCO DAAMAZÔNIA. Estimativa do orçamento para custeio de 1,0 hectare de arroz irrigado. Boa Vista: Banco da Amazônia, 2006.

BRONSON, K. F. et al. Use of ${ }^{15} \mathrm{~N}$-labeled soil in measuring nitrogen fertilizer recovery efficiency in transplanted rice. Soil Science Society of America Journal, Madison, v. 64, n. 1, p. 235-239, 2000.

CORDEIRO, A. C. C.; MOURÃO JÚNIOR, M. C.; MEDEIROS, R. D. de. Análise do agronegócio do arroz irrigado em Roraima - período 1981 a 2007. In: CONGRESSO BRASILEIRO DE ARROZ IRRIGADO, 6.; REUNIÃO DA CULTURA DO ARROZ IRRIGADO, 27., 2007, Porto Alegre. Anais... Porto Alegre: Orium, 2007. p. 719-721.

CORdeIRO, A. C. C.; MEdEIROS, R. D. de. BRS Jaçanã : nova cultivar de arroz irrigado para Roraima. Boa Vista: Embrapa Roraima, 2008. (Comunicado técnico, 2).

CORNÉLIO, V. M. de O. et al. Efeito de doses e épocas de aplicação de nitrogênio na incidência de doenças, produção e qualidade sanitária das sementes de arroz. Ciência e Agrotecnologia, Lavras, v. 31, n. 1, p. 47-52, jan./fev. 2007.

CRUZ, C. D. Programa Genes - versão Windows: aplicativo computacional em genética e estatística. Viçosa, MG: UFV, 2001.

CUTRIM, V. dos A. et al. BRS Jaçanã: cultivar de arroz irrigado para a região tropical. Santo Antônio de Goiás: Embrapa Arroz e Feijão, 2007. (Comunicado técnico, 140).

DUARTE, F. M. Perdas de nitrogênio por volatilização de amônia e eficiência da adubação nitrogenada no cultivo do arroz irrigado. 2006. 85 f. Dissertação (Mestrado em Ciência do Solo)-Universidade Federal de Santa Maria, Santa Maria, 2006.

EMPRESA BRASILEIRA DE PESQUISA AGROPECUÁRIA (Embrapa). Manual de métodos de pesquisa em arroz. Brasília, DF: Embrapa, 1977.

FAGERIA, N. K.; SANTOS, A. B. dos; CUTRIM, V. dos. Produtividade de arroz irrigado e eficiência de uso do nitrogênio influenciados pela fertilização nitrogenada. Pesquisa Agropecuária Brasileira, Brasília, DF, v. 42, n. 7, p. 1029-1034, jul. 2007. 
FAGERIA, N. K.; BALIGAR, V. C. Lowland rice response to nitrogen fertilization. Communications in Soil Science and Plant Analysis, New York, v. 32, n. 9-10, p. 14051429, 2001.

FAGERIA, N. K.; BALIGAR, V. C. Enhancing nitrogen use efficiency in crop plants. Advances in Agronomy, New York, v. 88, n. 1, p. 97-185, 2005.

FAGERIA, N. K.; STONE, L. F.; SANTOS, A. B. dos. Manejo da fertilidade do solo para o arroz irrigado. Santo Antônio de Goiás: Embrapa Arroz e Feijão, 2003a.

FAGERIA, N. K.; STONE, L. F.; SANTOS, A. B. dos. Manejo de nitrogênio em arroz irrigado. Santo Antônio de Goiás: Embrapa Arroz e Feijão. 2003b. (Circular técnica, 58).

INTERNATIONAL RICE RESEARCH INSTITUTE (IRRI). Standard evaluation system for rice. Manilla: INGER/Genetic Resources Center, 1996.

MEDEIROS, R. D. de et al. Resposta de cultivares de arroz irrigado a níveis de nitrogênio aplicados em cobertura no Estado de Roraima. In: CONGRESSO BRASILEIRO DE ARROZ IRRIGADO, 6. ; REUNIÃO DA CULTURA DO ARROZ IRRIGADO, 27., 2007, Porto Alegre. Anais... Porto Alegre: Orium, 2007a. p. 617-618.
MEDEIROS, R. D. de et al. Rendimento de cultivares de arroz irrigado BRS Jaburu e IRGA 417 sob níveis de nitrogênio aplicados em cobertura em várzea de Roraima. In: CONGRESSO BRASILEIRO DE ARROZ IRRIGADO, 6.; REUNIÃO DA CULTURA DO ARROZ IRRIGADO, 27., 2007, Porto Alegre. Anais... Porto Alegre: Orium, 2007b. p. 619-620.

MORAIS, O. P. de et al. Melhoramento genético. In: SANTOS, A. B. dos; STONE, L. F.; VIEIRA, N. R. de A. (Eds.). A cultura do arroz no Brasil. 2. ed. Santo Antônio de Goiás: Embrapa Arroz e Feijão, 2006. p. 289-358.

SCIVITTARO, W. B.; MACHADO, M. O. Adubação e calagem para a cultura do arroz irrigado. In: GOMES, A. S.; MAGALHÃES JÚNIOR, A. M. Arroz irrigado no Sul do Brasil. Brasília, DF: Embrapa Informação Tecnológica, 2004.

VAHL, L. C. Fertilidade de solos de várzea. In: GOMES, A. S.; PAULETTO, E. A. (Eds.). Manejo de solo e da água em áreas de várzeas. Pelotas: Embrapa Clima Temperado, 1999. p. 119-162. 